\title{
Rheological behavior of thermoreversible $\kappa$-carrageenan/nanosilica gels
}

\author{
A.L. Daniel-da-Silva ${ }^{\mathrm{a}, *}$, F. Pinto ${ }^{\mathrm{b}}$, J.A. Lopes-da-Silva ${ }^{\mathrm{b}}$, T. Trindade ${ }^{\mathrm{a}}$, B.J. Goodfellow ${ }^{\mathrm{a}}$, A.M. Gil ${ }^{\mathrm{a}}$ \\ a Department of Chemistry, CICECO, University of Aveiro, 3810-193 Aveiro, Portugal \\ ${ }^{\mathrm{b}}$ Department of Chemistry, QOPNA, University of Aveiro, 3810-193 Aveiro, Portugal
}

Received 2 November 2007; accepted 18 January 2008

Available online 1 February 2008

\begin{abstract}
The rheological behavior of silica/ $\kappa$-carrageenan nanocomposites has been investigated as a function of silica particle size and load. The addition of silica nanoparticles was observed to invariably impair the gelation process, as viewed by the reduction of gel strength and decrease of gelation and melting temperatures. This weakening effect is seen, for the lowest particle size, to become slightly more marked as silica concentration (or load) is increased and at the lowest load as particle size is increased. These results suggest that, under these conditions, the particles act as physical barriers to polysaccharide chain aggregation and, hence, gelation. However, for larger particle sizes and higher loads, gel strength does not weaken with size or concentration but, rather, becomes relatively stronger for intermediate particles sizes, or remains unchanged for the largest particles, as a function of load. This indicates that larger particles in higher number do not seem to increasingly disrupt the gel, as expected, but rather promote the formation of stable gel network of intermediate strength. The possibility of this being caused by the larger negative surface charge found for the larger particles is discussed. This may impede further approximation of neighboring particles thus leaving enough inter-particle space for gel formation, taking advantage of a high local polysaccharide concentration due to the higher total space occupied by large particles at higher loads. (c) 2008 Elsevier Inc. All rights reserved.
\end{abstract}

Keywords: Carrageenan; Silica; Rheology thermoreversible gel; Gel transition; Nanocomposite

\section{Introduction}

The interest in the use of biopolymers combined with nanosized silica to produce materials for biotechnological processes has long been recognized [1,2]. For example, biopolymer/silica nanocomposites are of interest for advanced biomedical materials such as tissue engineering, cell encapsulation and in the production of biosensors and bioreactors [3]. Also, following the sequence of recent studies of the role of biomolecules on silica polymerization taking place in several micro-organisms, biomimetic approaches to silica based hybrid materials have been carried out [4,5]. A wide variety of biopolymers, including gelatin, alginates, cellulose derivatives $[1-3,6-8]$ and carrageenans $[9,10]$ have been employed to produce biopolymer/silica nanocomposites. Carrageenans are water soluble and obtained from several species of marine red

\footnotetext{
* Corresponding author.

E-mail address: ana.luisa@ua.pt (A.L. Daniel-da-Silva).
}

algae. These polysaccharides form gels and are widely used as gelling agents in the food and pharmaceutical industries [11]. $\kappa$-carrageenan (Fig. 1a) bears one sulphate group per disaccharide unit and presents the best gelation properties, within the carrageenan family. It is well known that the gelation mechanism of $\kappa$-carrageenan involves a coil to helix conformational transition, a necessary condition for gelation, followed by helix aggregation to form an infinite three-dimensional network $[11,12]$ (Fig. 1b). The process is induced by cooling and promoted by monovalent cations such as potassium. The gelling temperature $T_{\mathrm{G}}$ usually increases for higher concentrations of biopolymer and of counterion.

In recent work reporting the preparation of $\kappa$-carrageenan/ silica nanocomposites, a sol-gel technique was used to generate nanoparticles of amorphous silica within the polymer matrix $[9,10]$. It was observed that the silica generated in situ reinforces the polysaccharide gel structure, which acts as a template for the biomineralization of silica. The formation of hydrogen bonds between the silica and the hydroxyl groups of the polysaccharide was advanced as an explanation for the 
(a)

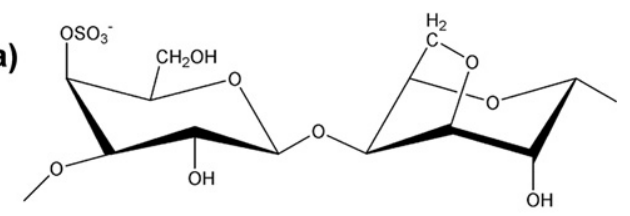

(b)

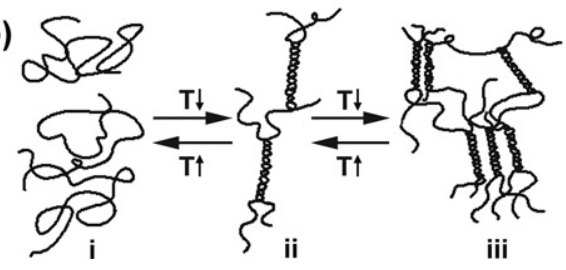

Fig. 1. (a) The structural disaccharide unit of $\kappa$-carrageenan and (b) a schematic representation of the $\kappa$-carrageenan gelation mechanism: (i) random coil conformation, (ii) helix conformation, (iii) aggregation of helices (adapted from Ref. [13]).

observed silica templating effect and the enhancement of the viscoelastic properties of the hybrid materials [10].

Alternatively to in situ synthesis, biopolymer/silica composites can also be prepared by simply dispersing morphologically well-defined $\mathrm{SiO}_{2}$ particles in the polymeric matrix. However, despite the numerous studies devoted to biopolymer $/ \mathrm{SiO}_{2}$ nanocomposites, little is known about the interaction between the biopolymer backbone and such $\mathrm{SiO}_{2}$ fillers and their influence on the final properties of the nanocomposites. Two recent studies of biopolymer composites have reported opposite effects arising from the addition of nanosized inorganic fillers to the biopolymer matrix $[8,14]$. One study reports that addition of nanosized $\mathrm{ZrO}_{2}$ to $\kappa$-carrageenan gels enhances viscoelastic properties with an increase of the elastic modulus by at least 2 orders of magnitude [14] and, in a second study, the addition of silicate to gelatin produces a weakening effect of the gel structure due to the formation of a precipitate that reduces gelatin concentration and, hence, decreases the strength of the gel formed [8].

The present work aims at understanding the effect of nanosized silica fillers on the gelation properties of $\kappa$-carrageenan, with particular interest in the effects of silica load and particle size. This should, not only aid in understanding $\kappa$-carrageenanbased systems, but also other biopolymer/nanoparticle systems based on structurally similar polysaccharides e.g. agarose or furcellaran $[11,15]$.

\section{Experimental}

\subsection{Materials}

Tetra-ethyl ortosilicate (TEOS) (98\%, Aldrich), ammonia (25\%, Merck), ethanol (Riedel-de Haën) and $\kappa$-carrageenan (Fluka Chemie, MW 300,000) were purchased and used as received.

\subsection{Synthesis of silica nanoparticles}

The synthesis of amorphous $\mathrm{SiO}_{2}$ nanoparticles was performed following the Stöber method [16] consisting of the
Table 1

The average particle diameter $(d)$ determined by SEM and DLS, the average specific area measured by BET $\left(a_{\mathrm{BET}}\right)$ and the geometric specific surface area (a) calculated using the SEM diameter

\begin{tabular}{lllll}
$\begin{array}{l}\text { Silica } \\
\text { samples }\end{array}$ & $\begin{array}{l}d_{\text {SEM }} \pm \sigma \\
(\mathrm{nm})\end{array}$ & $\begin{array}{l}d_{\text {DLS }} \pm \sigma \\
(\mathrm{nm})\end{array}$ & $\begin{array}{l}a_{\mathrm{BET}} \\
\left(\mathrm{m}^{2} / \mathrm{g}\right)\end{array}$ & $\begin{array}{l}a \\
\left(\mathrm{~m}^{2} / \mathrm{g}\right)\end{array}$ \\
\hline $\mathrm{SiO}_{2}-120$ & $118 \pm 13$ & $134 \pm 11$ & 31.4 & 23.1 \\
$\mathrm{SiO}_{2}-440$ & $444 \pm 26$ & $437 \pm 24$ & 14.2 & 6.14 \\
$\mathrm{SiO}_{2}-560$ & $563 \pm 35$ & $547 \pm 29$ & 5.79 & 4.84 \\
$\mathrm{SiO}_{2}-860$ & $856 \pm 26$ & $885 \pm 64$ & 4.02 & 3.19 \\
\hline
\end{tabular}

hydrolysis of TEOS in a homogeneous alcoholic medium and using ammonia as the catalyst. Four silica batches corresponding to distinct particle size distributions (Table 1) were prepared and will be designated hereafter by $\mathrm{SiO}_{2}-120, \mathrm{SiO}_{2}-440, \mathrm{SiO}_{2}-$ 560 and $\mathrm{SiO}_{2}-860$. The average size of the nanoparticles was controlled through the relative concentration of ammonium hydroxide, as described elsewhere [17].

\subsection{Characterization of the nanoparticles}

FT-IR analyses of silica nanoparticles were conducted using a Mattson 7000 spectrometer coupled to a horizontal attenuated total reflectance (ATR) cell, using 128 scans at a resolution of $4 \mathrm{~cm}^{-1}$. Particle morphology and particle size distribution were assessed by scanning electron microscopy (SEM). SEM was carried out using a FEG-SEM Hitachi S4100 microscope operating at $25 \mathrm{kV}$. For SEM analysis, an aliquot of a dilute particle suspension was allowed to air dry on glass slides and then were coated with evaporated carbon. For each sample, average particle size and standard deviation were determined by measuring the size of 50 particles in the SEM images. Hydrodynamic particle size was measured by Dynamic Light Scattering (DLS) and zeta potential was measured by electrophoretic light scattering, both using a Zetasizer Nanoseries instrument from Malvern Instruments. DLS was performed in stable suspensions diluted with ultrapure water (Type I, $18.2 \mathrm{M} \Omega \mathrm{cm}$ ) at $25^{\circ} \mathrm{C}$ and at a scattering angle of $90^{\circ}$. Samples for zeta potential were prepared at a constant $\mathrm{SiO}_{2}$ concentration, in $\mathrm{KCl} 0.25 \mathrm{M}$ to control ionic strength (conductivity of $35-36 \mathrm{mS} / \mathrm{cm}$ ), and the $\mathrm{pH}$ was adjusted by adding appropriate volumes of stock solutions of $\mathrm{HCl}$ or $\mathrm{KOH}$. Measurements were replicated four times and the average value was calculated, with an experimental error lower than $10 \%$. The specific surface area of the silica particles was determined with nitrogen adsorption BET measurements performed with a Gemini Micromeritics instrument.

\subsection{Rheological measurements}

The rheological behavior of the gels was characterized via small amplitude oscillatory shear measurements using a Bohlin CVOHR 120 rheometer with parallel plate geometry (corrugated plate, $40 \mathrm{~mm}$ diameter, $1 \mathrm{~mm}$ gap). The nanocomposites were prepared by dispersing the silica in a $10 \mathrm{~g} / \mathrm{L} \kappa$-carrageenan solution under sonication, at approximately $50^{\circ} \mathrm{C}$, and their ionic strength was assessed by conductivity measurements $(1.2-1.7 \mathrm{mS} / \mathrm{cm})$. Composites with silica loads between 


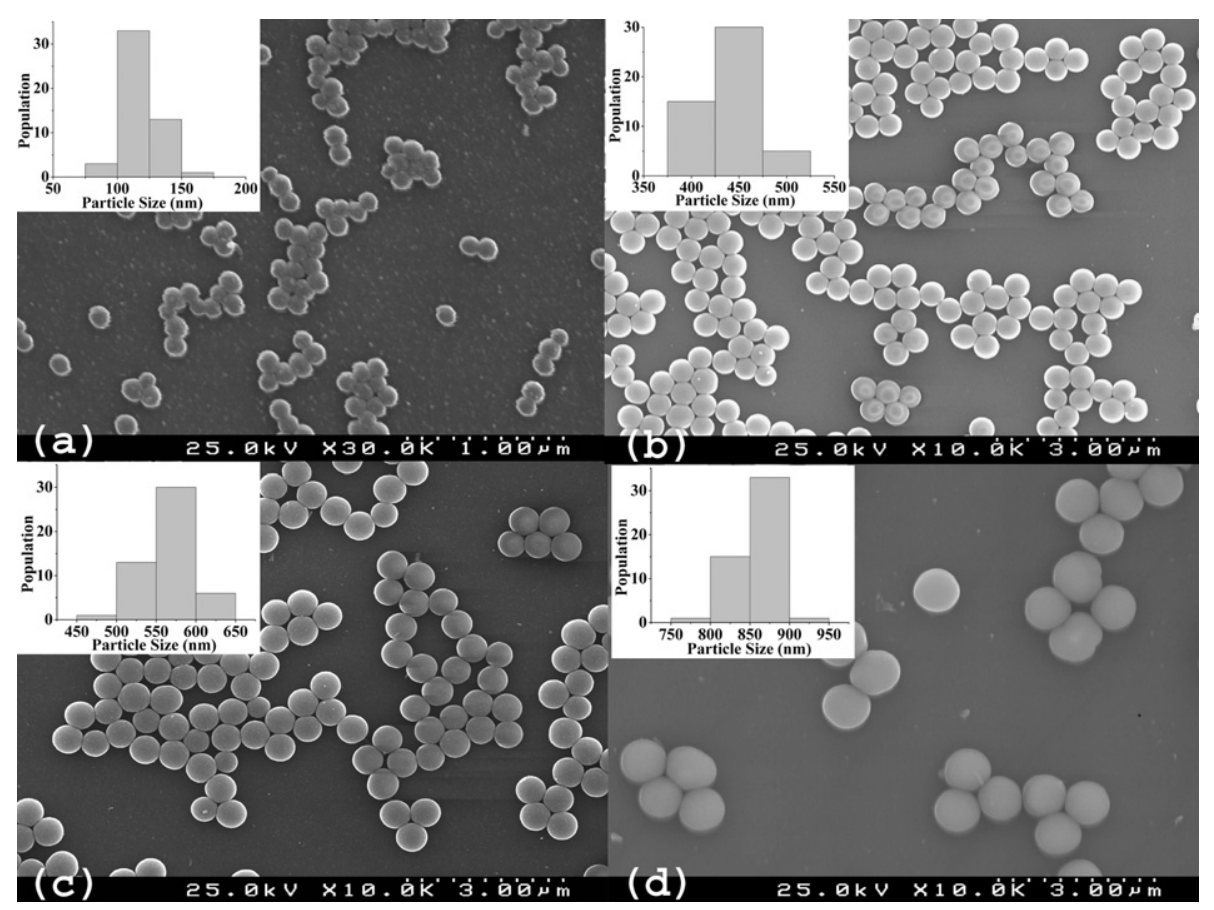

Fig. 2. $\mathrm{SEM}$ images of $\mathrm{SiO}_{2}$ nanoparticles and respective particle size histograms: (a) $\mathrm{SiO}_{2}-120$, (b) $\mathrm{SiO}_{2}-440$, (c) $\mathrm{SiO}_{2}-560$ and (d) $\mathrm{SiO}_{2}-860$.

5 and $50 \mathrm{wt} \%$ (related to the biopolymer content) were prepared, all giving homogeneous samples, apparently precipitatefree. However, the possibility of some flocculation taking place, as usually noted for silica-based systems, may not be ruled out. Immediately after preparation, approximately $1.6 \mathrm{~mL}$ of the composite was transferred to the rheometer measuring system equilibrated at $40^{\circ} \mathrm{C}$. The exposed surface of the sample was covered with mineral oil to minimize solvent evaporation. The gelation was monitored by measuring both storage $\left(G^{\prime}\right)$ and loss $\left(G^{\prime \prime}\right)$ moduli as a function of temperature, from 40 to $20^{\circ} \mathrm{C}$ at $1{ }^{\circ} \mathrm{C} / \mathrm{min}$, at a frequency of $2 \mathrm{rad} / \mathrm{s}$. Gel curing at $20^{\circ} \mathrm{C}$ was then followed for a period of $17 \mathrm{~h}$ under the same frequency and strain conditions. Finally, a frequency sweep test was done at $20^{\circ} \mathrm{C}$, from 0.1 to $100 \mathrm{rad} / \mathrm{s}$, to assess the frequency dependence of the viscoelastic properties of the gel. The melting of the gel was monitored by measuring the viscoelastic moduli as a function of temperature from 20 to $50^{\circ} \mathrm{C}$, at $1{ }^{\circ} \mathrm{C} / \mathrm{min}$. Strain amplitude of 0.01 , within the linear viscoelastic regime, was used in all measurements.

\section{Results and discussion}

\subsection{Characterization of $\mathrm{SiO}_{2}$ nanoparticles}

As described above, small variations in the synthetic conditions allowed four batches of amorphous $\mathrm{SiO}_{2}$ nanoparticles with different particle size distributions (Table 1) to be prepared. The typical vibrational bands of amorphous $\mathrm{SiO}_{2}$ were easily identified for all batches by FT-IR (Fig. S1, supplementary information): the $\mathrm{OH}$ stretching band $\left(\nu_{\mathrm{OH}}\right)$ at $3300 \mathrm{~cm}^{-1}$, the band centered at $1050 \mathrm{~cm}^{-1}$ assigned to the $\mathrm{Si}-\mathrm{O}-\mathrm{Si}$ asymmetric stretching vibration and the band at $950 \mathrm{~cm}^{-1}$, due to the $\mathrm{Si}-\mathrm{OH}$ stretching mode. In addition, $\mathrm{Si}-\mathrm{O}-\mathrm{Si}$ bending vi- brations give rise to bands at 790,550 and $440 \mathrm{~cm}^{-1}[5,18]$. No bands assignable to residual organic compounds were observed for any of the $\mathrm{SiO}_{2}$ samples.

The SEM images and size histograms of the $\mathrm{SiO}_{2}$ batches prepared in this work are shown in Fig. 2. The former confirm the well-defined spherical morphology of $\mathrm{SiO}_{2}$ particles and the histograms show that narrow particle size distributions have been achieved for all powdered samples.

The average number-weighted diameter $(d)$ and standard deviation $(\sigma)$ of the four batches of $\mathrm{SiO}_{2}$ particles are shown in Table 1. Generally, there is good agreement between the $d$ values measured by SEM and those measured by DLS, which shows that there is a good dispersion in aqueous media. The BET specific surface areas $\left(a_{\mathrm{BET}}\right)$ of the $\mathrm{SiO}_{2}$ particles, also listed in Table 1, were compared with the specific surface areas (a) calculated using SEM measurements, making use of the $a=6 /(d \times \rho)$ relationship, where $\rho$ is particle density (Table 1). This parameter was taken as $2.20 \mathrm{~g} / \mathrm{cm}^{3}$, which is the generally accepted value of the density value of amorphous $\mathrm{SiO}_{2}$ [19]. The BET specific surface areas were found to be consistently higher than the geometric specific surface area values which suggests the existence of some degree of roughness or porosity on the $\mathrm{SiO}_{2}$ particle surfaces.

The zeta potential of the $\mathrm{SiO}_{2}$ particles was measured as a function of solution $\mathrm{pH}$ (Fig. 3) for all batches, in order to measure particle charge under the experimental conditions employed. Although the ionic strength used for zeta potential measurements was different from the gel, the relative differences in the zeta potential with particle size are maintained (data not shown). The isoelectric point of colloidal silica was found to be in the range $\mathrm{pH} 3-4$ so that, at higher $\mathrm{pH}$ 's, the surface potential of $\mathrm{SiO}_{2}$ particles becomes negative. In addition, at the $\mathrm{pH}$ of the $\kappa$-carrageenan solutions ( $\mathrm{pH} 8.5-9.0$ ), 


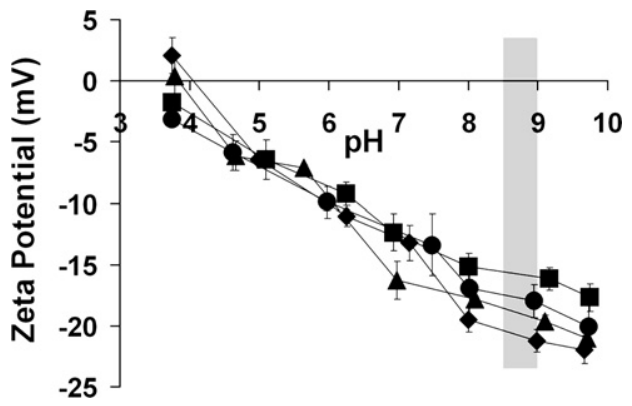

Fig. 3. Influence of $\mathrm{SiO}_{2}$ particle size on zeta potential as a function of the solution pH (electrolyte solution: $0.25 \mathrm{M} \mathrm{KCl}$ ): $\mathrm{SiO}_{2}-120$ (ם), $\mathrm{SiO}_{2}-440$ (ム), $\mathrm{SiO}_{2}-560(\bullet)$ and $\mathrm{SiO}_{2}-860(\mathbf{\square})$. The zone highlighted in grey corresponds to the $\mathrm{pH}$ range of the $\kappa$-carrageenan solutions used in this work.

the zeta potential of $\mathrm{SiO}_{2}$ particles is seen to depend on particle size (Fig. 3), becoming more negative as $\mathrm{SiO}_{2}$ particle size increases. This is somewhat unexpected since, assuming identical surface compositions for all batches, the average surface charge should be proportional to the surface area and, therefore, more negative for small particles. The results obtained may indicate that the surface of the silica particles may differ in composition which, together with some degree of surface porosity/roughness, may play an important role in determining surface charge and, hence, interaction with non-silica agents.

\subsection{Effects of $\mathrm{SiO}_{2}$ fillers on formation, curing and melting of $\kappa$-carrageenan gels}

Blends of $\kappa$-carrageenan with $\mathrm{SiO}_{2}$ particles were prepared and their rheological behavior studied by small amplitude oscillatory shear measurements. This was carried out in three consecutive steps: (1) the initial gelation of the polysaccharide or blend induced by cooling, (2) the subsequent curing of the gel at $20^{\circ} \mathrm{C}$ and characterization of the cured gel and (3) the melting of the gel.

\subsubsection{Gelation}

Fig. 4 illustrates the variation of both $G^{\prime}$ and $G^{\prime \prime}$ during gelation induced by cooling for $\kappa$-carrageenan alone (in black) and for the blend of $\kappa$-carrageenan/ $/ \mathrm{SiO}_{2}-120$ with $30 \mathrm{wt} \% \mathrm{SiO}_{2}$ (in grey). The gelation process is characterized by a sharp increase of both storage and loss moduli [12]. The beginning of the process is dominated by the viscous behavior of the system $\left(G^{\prime \prime}>G^{\prime}\right)$ and the elastic behavior dominates after gelation $\left(G^{\prime}>G^{\prime \prime}\right)$. During gelation, the connectivity between the basic structural units of the polymer increases and the gradual development of the network structure induces, as expected, a progressive increase in storage modulus $\left(G^{\prime}\right)$. The curve obtained for the blend of $\kappa$-carrageenan $/ \mathrm{SiO}_{2}-120$ with $30 \mathrm{wt} \%$ $\mathrm{SiO}_{2}$ (Fig. 4) shows that the gelation temperature decreases and, in the gel state, both viscoelastic moduli are lower in the composite than in pure carrageenan, similar observations having been noted for all the remaining blends. This indicates that the presence of silica particles impairs the development of the $\kappa$-carrageenan network.

The gelling temperatures $\left(T_{\mathrm{G}}\right)$ were registered for both pure carrageenan and blends, for comparison. The experimental

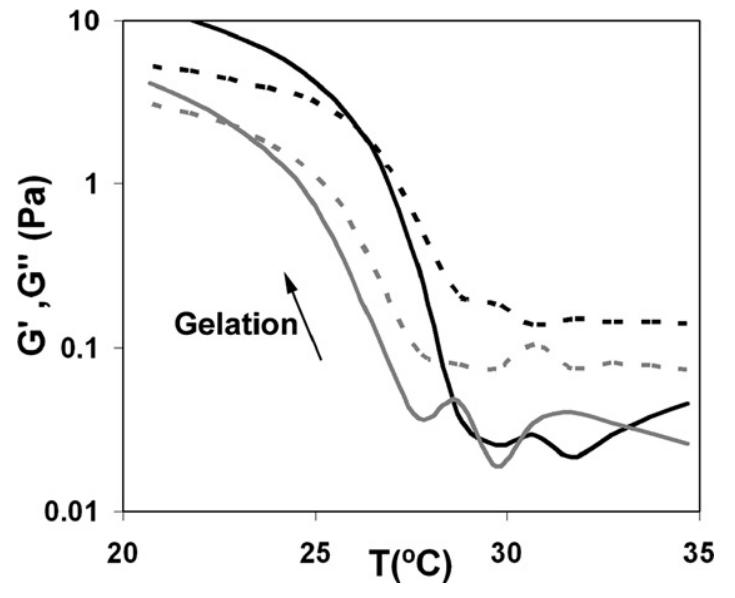

Fig. 4. Storage $\left(G^{\prime},-\right)$ and loss moduli $\left(G^{\prime \prime},---\right)$ as a function of temperature for pure $\kappa$-carrageenan (black curves) and a $\kappa$-carrageenan $/ \mathrm{SiO}_{2}-120$ blend (10 g/L $\kappa$-carrageenan) with $30 \mathrm{wt} \% \mathrm{SiO}_{2}$ (grey curves) during gelation.
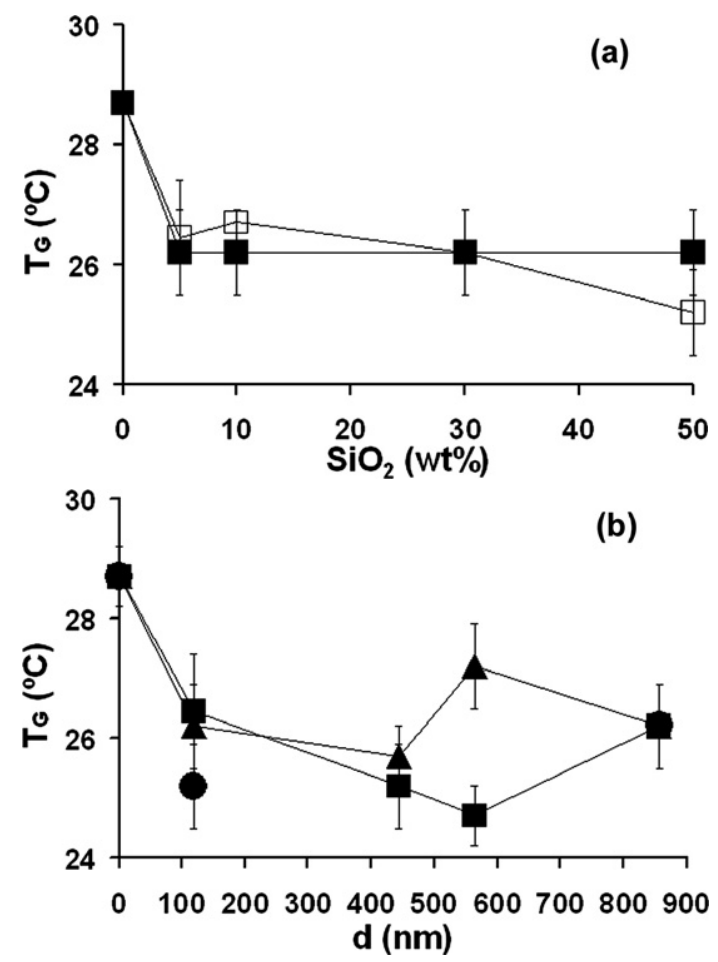

Fig. 5. The effect of (a) $\mathrm{SiO}_{2}$ loading on the gelation temperature $\left(T_{\mathrm{G}}\right)$ of the composites (10 g/L $\kappa$-carrageenan) prepared with $\mathrm{SiO}_{2}-120(\square)$ and $\mathrm{SiO}_{2}-860$ (ロ) and (b) $\mathrm{SiO}_{2}$ particle size on $T_{\mathrm{G}}$ for $5(\boldsymbol{\square}), 30(\boldsymbol{\Lambda})$ and $50(\bullet) \mathrm{wt} \% \mathrm{SiO}_{2}$.

detection of gelling (sol-gel transition) and melting (gel-sol transition) temperatures of this type of systems is not always straightforward and different criteria have been proposed $[15,20]$. Here, $T_{\mathrm{G}}$ was calculated as the onset temperature of the increasing ramp of the storage modulus $\left(G^{\prime}\right)$, under cooling conditions. Figs. $5 \mathrm{a}$ and $5 \mathrm{~b}$ show that $T_{\mathrm{G}}$ decreases with the addition of $\mathrm{SiO}_{2}$ particles, for the different particle sizes and loads investigated. Together with the decrease in viscoelastic moduli (and loss factor increases), this decrease in $T_{\mathrm{G}}$ indicates that a weaker gel structure is formed upon the addition of $\mathrm{SiO}_{2}$ nanoparticles. A similar weakening effect of the structure of the gel has been reported for silicate/gelatin composites [8] and 
proposed to be caused by the formation of silica/gelatin precipitates. However, no formation of precipitates was noted in the samples studied here, with all $\mathrm{SiO}_{2}$ filled $\kappa$-carrageenan samples producing homogeneous gels. A possible explanation for the weaker strength of the $\kappa$-carrageenan $/ \mathrm{SiO}_{2}$ nanocomposite gels is simply that the $\mathrm{SiO}_{2}$ nanoparticles act as physical barriers towards the gelation process, either by impeding the formation of the helices and/or the formation of the helical aggregates (Fig. 1).

A closer study of the effects of particle size and load was carried out and Fig. 5a shows that, for $\mathrm{SiO}_{2}-120$ particles, there is a slight decrease in $T_{\mathrm{G}}$, whereas no changes are noted for the $\mathrm{SiO}_{2}-860$ particles. This decrease, however small, is consistent with the $\mathrm{SiO}_{2}$ nanoparticles acting as steric barriers, pushing apart the polysaccharide helices and hindering their aggregation. This results in further cooling being necessary to promote chain aggregation and gelling. On this basis, a similar effect would also be expected for increasing loads of larger particles e.g. $\mathrm{SiO}_{2}-860$. The fact that this is not observed (Fig. 5a) suggests that an additional effect may be taking place, resulting in the strengthening of the gel at higher loads. This is again noted when the detailed $T_{\mathrm{G}}$ dependence on particle size is considered (Fig. 5b). For a 5\% load (squares), $T_{\mathrm{G}}$ decreases gradually up to particle sizes close to $600 \mathrm{~nm}$, as expected if a physical hindrance effect prevails; however, an increase in $T_{\mathrm{G}}$ is then seen for $\mathrm{SiO}_{2}-860$ particles. For a $30 \%$ load (triangles), a $T_{\mathrm{G}}$ increase is noted, starting at smaller particle sizes $\left(\mathrm{SiO}_{2}-560\right)$. Considering the increase in particle negative charge with increasing size (Fig. 3), it may be suggested that it is the larger charge of the larger particles that competes with the effect of steric hindrance. The higher particle charge may have two possible effects on the system, one being the adsorption of a higher load of potassium ions at the particle surface, as noted before [21], which would leave less cations free to act as electrostatic stabilizers in the junction gels and, thus, resulting in a weaker gel. A second possible effect relates to the higher repulsion between larger particles which would impede their physical approximation even at higher loads. As particle load increases, the effect would not be an increasing disruption of the gel but rather an effect of higher local polysaccharide concentration in interparticle space, due to the increasing total space occupied by the silica at higher loads. The polysaccharide is thus squeezed into inter-particle space which is kept large enough due to strong inter-particle repulsion, for gelation to occur. The resulting system may be seen as a gel stabilized by large negative particles which occupy the network empty space pores. This stabilizing effect has been known to occur for starch gels, where starch granules [22] or added inorganic fillers [23] have a reinforcement effect of the amylase network.

We note that the weakening effect that arises from the addition of $\mathrm{SiO}_{2}$ nanoparticles could be also related to the adsorption of carrageenan chains onto silica surface, thus perturbing chain aggregation and reducing gelation temperature and gel strength. However, because both $\kappa$-carrageenan molecules and the $\mathrm{SiO}_{2}$ surfaces are negatively charged, electrostatic repulsions should predominate and therefore the amount of carrageenan adsorbed onto the silica surface would be mini-

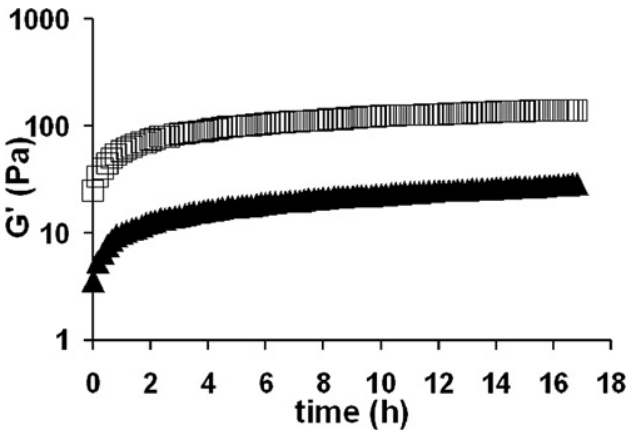

Fig. 6. The evolution of $G^{\prime}$ for $\kappa$-carrageenan ( $\square$ ) and a $\kappa$-carrageenan/ $\mathrm{SiO}_{2}-120$ blend $\left(10 \mathrm{~g} / \mathrm{L} \kappa\right.$-carrageenan) with $10 \mathrm{wt} \% \mathrm{SiO}_{2}(\boldsymbol{\Delta})$ during the $17 \mathrm{~h}$ curing period, at $20^{\circ} \mathrm{C}$.

mal and insufficient to justify the pronounced effects on gel strength. A similar explanation was pointed out in a previous work [24] to explain the low $\kappa$-carrageenan adsorption on a macroporous silica glass. In addition, regarding the critical overlap concentration for $\kappa$-carrageenan (ca. $0.08 \mathrm{wt} \%$ ) [25], the polymer solutions are clearly in the semidilute regime and therefore a substantial degree of chain overlapping and entanglement between the $\kappa$-carrageenan chains before gelation is expected. Under this concentration regime, the entanglement between polymer chains would restrict the free motion of each chain thus delaying or even hindering any possible adsorption of the polymer on the particle surface.

\subsubsection{Cured gels}

Fig. 6 illustrates the variation of $G^{\prime}$ during the curing of the gels obtained for $\kappa$-carrageenan alone and for the $\kappa$-carrageenan $/ \mathrm{SiO}_{2}-120\left(10 \mathrm{wt} \% \mathrm{SiO}_{2}\right)$ composite. For pure $\kappa$ carrageenan, $G^{\prime}$ was of the order of $20 \mathrm{~Pa}$ immediately after the temperature reached $20^{\circ} \mathrm{C}$, after gelling, and increased up to $150 \mathrm{~Pa}$, after $17 \mathrm{~h}$ at $20^{\circ} \mathrm{C}$. Upon addition of $\mathrm{SiO}_{2}$, initial $G^{\prime}$ values were lower but the curves followed similar trends. For none of the systems studied here did the storage modulus attain a constant value after $17 \mathrm{~h}$. This non-equilibrium behavior during curing, for long periods of time, reflects the ongoing reorganization of the network and is common in many gelation processes, especially for physical gels [26].

In order to examine more closely the viscoelastic properties of the cured $\kappa$-carrageenan $/ \mathrm{SiO}_{2}$ gels, angular frequency sweep tests were performed after a curing period of $17 \mathrm{~h}$. The mechanical spectra of $\kappa$-carrageenan $/ \mathrm{SiO}_{2}$ gels, prepared with different concentrations of the smallest and largest $\mathrm{SiO}_{2}$ nanoparticles $\left(\mathrm{SiO}_{2}-120\right.$ and $\mathrm{SiO}_{2}-860$, respectively), are depicted in Figs. 7a and $7 \mathrm{~b}$.

For pure $\kappa$-carrageenan, $G^{\prime}$ shows low frequency dependence which is indicative of a true gel-like structure. Upon addition of silica $\mathrm{SiO}_{2}-120$ (Fig. 7a), $G^{\prime}$ decreases and its dependence upon frequency increases, reflecting the formation of a less elastic network. This effect becomes slightly more marked as the silica load increases, although for $5 \mathrm{wt} \% G^{\prime}$ was unexpectedly low with values similar to those obtained for $30 \mathrm{wt} \%$. The overall tendency is consistent with the changes observed in $T_{\mathrm{G}}$ (Fig. 5a) and the slightly higher frequency de- 

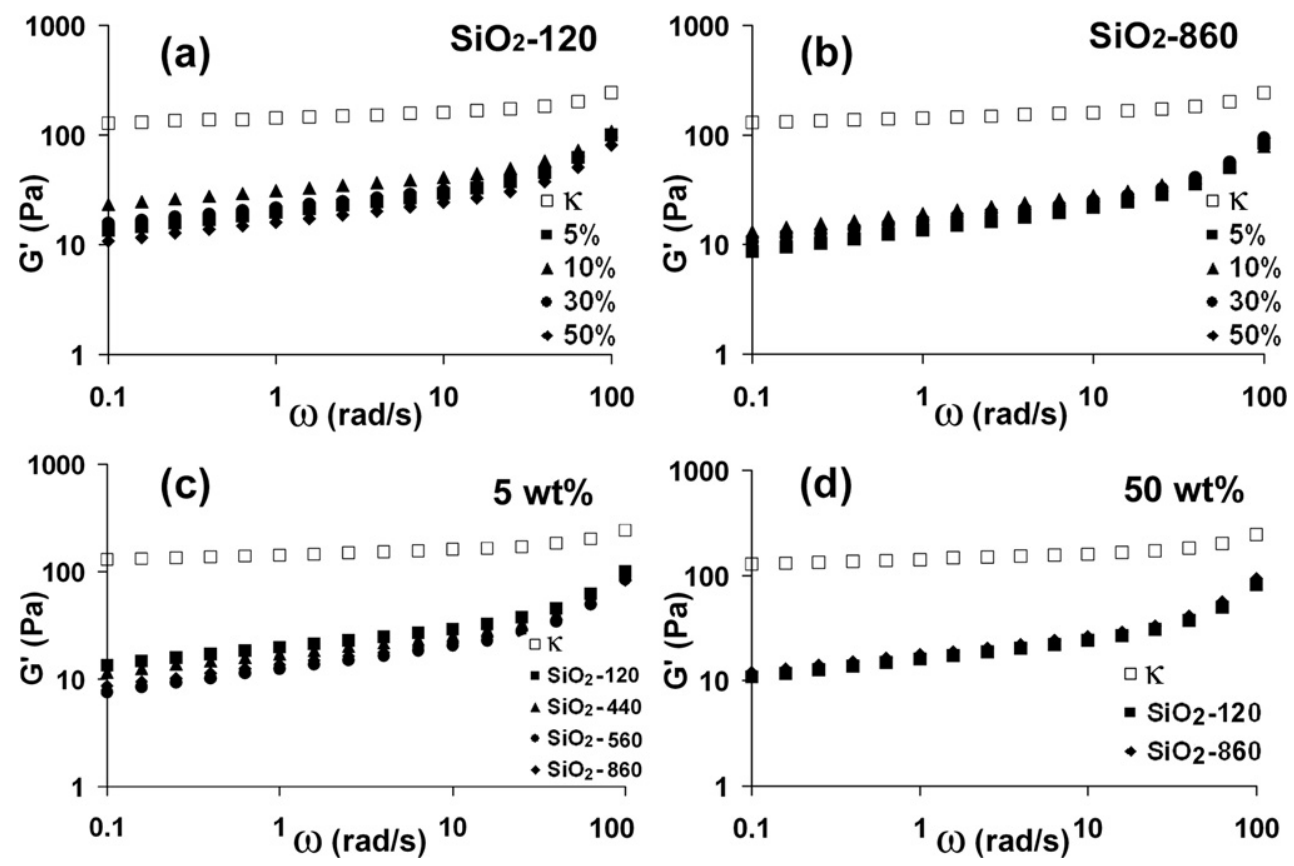

Fig. 7. The mechanical spectra $\left(G^{\prime}\right)$ of the composites $\left(10 \mathrm{~g} / \mathrm{L} \kappa\right.$-carrageenan) at $20^{\circ} \mathrm{C}$ : the effect of $\mathrm{SiO}_{2}$ loading for composites prepared with (a) silica $\mathrm{SiO}{ }_{2}-120$ and (b) $\mathrm{SiO}_{2}-860$ and the effect of $\mathrm{SiO}_{2}$ particle size for (c) $5 \mathrm{wt} \%$ and (d) $50 \mathrm{wt} \% \mathrm{SiO}_{2}$.

pendence of $G^{\prime}$, as the concentration of silica increases (even at low frequencies), is indicative of a weaker gel structure. As expected, in addition to the decrease in gel rigidity, a clear three-fold increase of $\tan \delta\left(=G^{\prime \prime} / G^{\prime}\right)$ was also observed upon silica addition (results not shown), indicating that the viscous character of the composite gels increases significantly due to the presence of silica nanoparticles, i.e. loss processes and the molecular rearrangements within the network are now more marked. A slight increase of $\tan \delta$ is seen at lower frequencies, for both pure polysaccharide and the composites, as expected for physically associating systems [27]. At higher frequencies, a sharp decrease in $\tan \delta$ is observed for both pure $\kappa$-carrageenan and the composites meaning that, at short solicitation times, the networks of the pure matrix and the composites respond similarly. The composites prepared with the largest particles $\left(\mathrm{SiO}_{2}-860\right)$ (Fig. 7b) also show smaller $G^{\prime}$ and higher $\tan \delta$ (not shown) than the $\kappa$-carrageenan matrix but no significant dependence on load is noted. Again, this is consistent with the noted absence of $T_{\mathrm{G}}$ variations for this sample (Fig. 5a).

In Figs. $7 \mathrm{c}$ and $7 \mathrm{~d}$, the effect of particle size on the storage modulus is shown for the two limiting concentrations. At $5 \mathrm{wt} \%$, it is clear that the effect of particle size in the 100 $850 \mathrm{~nm}$ range is small, showing a slight tendency for $G^{\prime}$ to decrease and for $\tan \delta$ to increase (not shown), with increasing particle size. This is in agreement with a mechanism that considers silica particles as physical barriers to gel formation. On the other hand, at $50 \mathrm{wt} \%, G^{\prime}$ (and $\tan \delta$ ) is virtually the same for the two extreme particle sizes. These results are in agreement with the suggestion that, for $\mathrm{SiO}_{2}-860$, the effect of stronger electrostatic repulsion between $\mathrm{SiO}_{2}$ particles, with higher zeta potentials (Fig. 3), may overcome the effect of physical steric barriers.
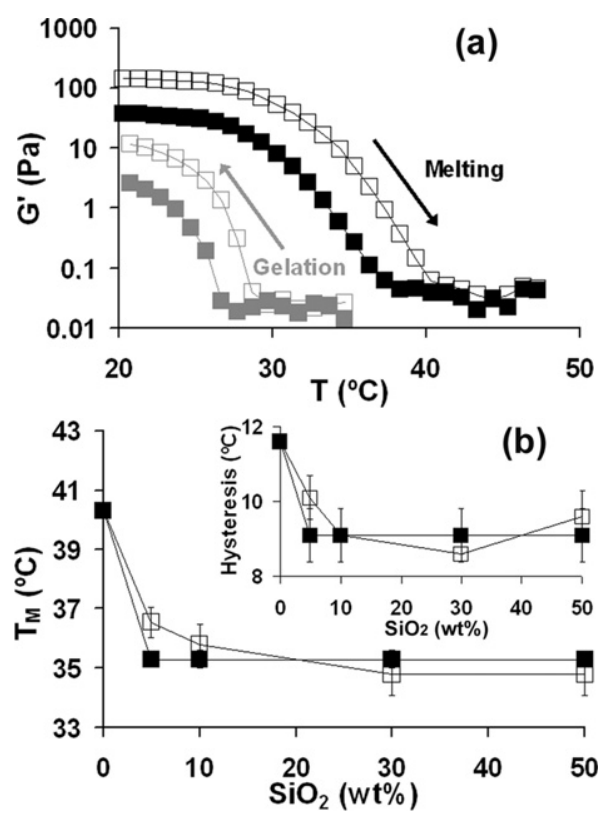

Fig. 8. (a) Hysteresis loop for $\kappa$-carrageenan (open symbols) and a composite containing $30 \mathrm{wt} \% \mathrm{SiO}_{2}-120$ (full symbols); (b) variation of the melting temperature $\left(T_{\mathrm{M}}\right)$ and hysteresis width (inset) with $\mathrm{SiO}_{2}$ loading for composites prepared with silica $\mathrm{SiO}_{2}-120(\square)$ and $\mathrm{SiO}_{2}-860(\mathbf{\square})$

\subsubsection{Melting}

Fig. 8a illustrates the variation of $G^{\prime}$ during gelation and melting, for pure $\kappa$-carrageenan and $\kappa$-carrageenan $/ \mathrm{SiO}_{2}-120$ $(30 \mathrm{wt} \%)$. As for the gelling process, the addition of nanosized $\mathrm{SiO}_{2}$ particles to $\kappa$-carrageenan results in lower melting (i.e. gel-to-sol transition) temperatures $\left(T_{\mathrm{M}}\right)$, compared to the pure biopolymer. The variation of $T_{\mathrm{M}}$ with $\mathrm{SiO}_{2}$ loading is shown in Fig. 8b, indicating that, for $\mathrm{SiO}_{2}-120$ (open squares), $T_{\mathrm{M}}$ decreases gradually as the silica content increases. On the other 
hand, for $\mathrm{SiO}_{2}-860$ (filled squares) the effect is independent of silica load.

Since the effect of $\mathrm{SiO}_{2}$ addition on $T_{\mathrm{M}}$ is more pronounced than that for $T_{\mathrm{G}}$, a change in the hysteresis magnitude (given as the difference between melting and gelling temperatures) is expected. For $\kappa$-carrageenan, a hysteresis loop of $11.6^{\circ} \mathrm{C}$ was observed, consistent with information reported in the literature [11] (insert in Fig. 8b). Upon addition of $\mathrm{SiO}_{2}$, the hysteresis decreases due to the more marked $T_{\mathrm{M}}$ decrease and, although a slight variation is noted as a function of load, for the smallest particles, the effect is again approximately constant for higher values of $\mathrm{SiO}_{2}-860$ load.

\section{Conclusions}

It was found that the addition of silica nanoparticles impairs the gelation of $\kappa$-carrageenan polysaccharide, as viewed by the reduction of viscoelastic moduli and decrease of gelling and melting temperatures.

The effect exerted by silica nanoparticles was seen to depend on silica load and particle size. For the lowest particle size and at the lowest load the particles apparently act as steric barriers to chain aggregation and hence make gelling more difficult. For larger particles and at higher loads a stabilizing effect is observed and a gel network with intermediate strength is obtained. The stronger inter-particle repulsion expected for larger particles and the local increase in polymer concentration in inter-particle spaces for high silica loads were proposed as possible explanations for this behavior.

\section{Acknowledgments}

This work was partially funded by FCT and FEDER (Project PTDC/QUI/67712/2006). A.L. Daniel da Silva thanks CICECO-Centro de Investigação em Materiais Cerâmicos e Compósitos (University of Aveiro) for funding this work.

\section{Supplementary information}

The online version of this article contains additional supplementary information.
Please visit DOI: 10.1016/j.jcis.2008.01.035.

\section{References}

[1] Y. Fukushima, K. Okamura, K. Imai, H. Matai, Biotechnol. Bioeng. 32 (1988) 584.

[2] O. Heichal-Segal, S. Rappoport, S. Braun, Bio/technology 13 (1995) 798.

[3] T. Coradin, J. Allouche, M. Boissiere, J. Livage, Curr. Nanosci. 2 (2006) 219.

[4] P.J. Lopez, C. Gautier, J. Livage, T. Coradin, Curr. Nanosci. 1 (2005) 73.

[5] J. Allouche, M. Boissière, C. Hélary, J. Livage, T. Coradin, J. Mater. Chem. 16 (2006) 3120.

[6] S. Yano, Polymer 35 (1994) 5565.

[7] M. Boissière, P.J. Meadows, R. Brayner, C. Hélary, J. Livage, T. Coradin, J. Mater. Chem. 16 (2006) 1178.

[8] T. Coradin, S. Bah, J. Livage, Colloids Surf. B 35 (2004) 53.

[9] M. Boissière, A. Tourrette, J.M. Devoisselle, F. Di Renzo, F. Quignard, J. Colloid Interface Sci. 294 (2006) 109.

[10] Y.A. Shchipunov, J. Colloid Interface Sci. 268 (2003) 68.

[11] L. Piculell, in: A.M. Stephen (Ed.), Food Polysaccharides and Their Applications, Marcel Dekker, New York, 1995, pp. 205-217.

[12] J. Borgström, L. Piculell, C. Viebke, Y. Talmon, Int. J. Biol. Macromol. 18 (1996) 223.

[13] A.J. Millán, R. Moreno, M.I. Nieto, J. Eur. Ceram. Soc. 22 (2002) 2209.

[14] E. Gregorová, W. Pabst, J. Štětina, J. Eur. Ceram. Soc. 26 (2006) 1185.

[15] J.A. Lopes da Silva, M.A. Rao, J.-T. Fu, in: M.A. Rao, R.W. Hartel (Eds.), Phase/State Transitions in Foods, Marcel Dekker, New York, 1998, pp. 111-157.

[16] W. Stöber, A. Fink, E. Bohn, J. Colloid Interface Sci. 26 (1968) 62.

[17] R.J.B. Pinto, P.A.A. Marques, A.M. Barros-Timmons, T. Trindade, C. Pascoal Neto, Compos. Sci. Technol. 68 (2008) 1088.

[18] C.Q. Ning, Y. Greish, A. El-Ghannam, J. Mater. Sci. Mater. Med. 15 (2004) 1227.

[19] L. Jelinek, E. Kováts, Langmuir 10 (1994) 4225.

[20] S.M. Tosh, A.G. Marangoni, Appl. Phys. Lett. 84 (2004) 4242.

[21] G.V. Franks, J. Colloid Interface Sci. 249 (2002) 44.

[22] A.C. Eliasson, J. Texture Stud. 17 (1986) 253.

[23] B.-S. Chiou, E. Yee, G.M. Glenn, W.J. Orts, Carbohydr. Polym. 59 (2005) 467.

[24] S.Yu. Bratskaya, V.A. Avramenko, Colloid J. 63 (2001) 137.

[25] E. Pelletier, C. Viebke, J. Meadows, P.A. Williams, Biomacromolecules 2 (2001) 946.

[26] J.A. Lopes da Silva, M.A. Rao, in: M.A. Rao (Ed.), Rheology of Fluid and Semisolid Foods, Aspen Publishers Incorporation, Maryland, 1999, p. 319 .

[27] D.J. Power, A.B. Rodd, L. Paterson, D.V. Boger, J. Rheol. 42 (1998) 1021. 